\title{
POLÍTICAS DE TECNOLOGIAS EDUCACIONAIS: INTERDISCIPLINARIDADES E PRÁTICAS DE INCLUSÃO DIGITAL
}

\author{
EDUCATIONAL TECHNOLOGY POLICIES: INTERDISCIPLINARITIES \\ AND DIGITAL INCLUSION PRACTICES
}

\section{POLÍTICAS DE TECNOLOGÍA EDUCATIVA: INTERDISCIPLINARIEDAD Y PRÁCTICAS DE INCLUSIÓN DIGITAL}

\author{
Roberta Mirnas de Oliveira Gomes ${ }^{\mathrm{I}}$ \\ Jean Mac Cole Tavares Santos ${ }^{\mathrm{I}}$ \\ ${ }^{\text {I }}$ Universidade do Estado do Rio Grande do Norte (UERN), Mossoró/RN, Brasil
}

RESUmo O trabalho propõe analisar as políticas de tecnologias educacionais Programa Nacional de Tecnologia Educacional - PROINFO e Programa um Computador por Aluno - PROUCA em diálogo com a interdisciplinaridade. Para abordar os programas como política, utiliza-se como referencial Ball e Bowe (1998) quando discutem o ciclo de políticas. A interdisciplinaridade como relação pedagógica e dialógica é discorrida a partir de Fazenda (2008) em colaboração ainda com Souza e Fazenda (2017), que relacionam tecnologias, currículo e interdisciplinaridade. A discussão sobre inclusão digital como processo de apropriação das tecnologias digitais de forma ativa, participativa e propositiva é contemplada por Pereira (2006) e Bonilla (2005). Conduziu-se a pesquisa a partir de análise documental em documentos oficiais dos programas governamentais. Além disso, um formulário eletrônico foi elaborado e enviado a três docentes de duas escolas públicas, atores de tais propostas. Os resultados evidenciam que as propostas dos programas se apresentam propícias ao desenvolvimento de práticas interdisciplinares, todavia, as lacunas sentidas pelos docentes no contexto da prática, ecoam como fator desfavorável à imersão das tecnologias digitais sob a perspectiva interdisciplinar.

Palavras-chave: Políticas PÚblicas; Currículo interdisciplinar; InClusão digital.

ABSTRaCr This work proposes to analyze the educational technology policies Programa Nacional de Tecnologia Educacional - PROINFO (National Program for Educational Technology) and Programa um Computador por Aluno - PROUCA (Program One Computer per Student) in an interdisciplinarity dialogue. To approach programs as a policy, Ball 
and Bowe (1998) are used as a reference when discussing the policy cycle. Its discussed Interdisciplinarity as a pedagogical and dialogical relationship as from Fazenda (2008) in collaboration with Souza and Fazenda (2017) that relate technologies, curriculum, and interdisciplinarity. The discussion on digital inclusion as a process of appropriating digital technologies in an active, participatory, and purposeful way is contemplated by Pereira (2006) and Bonilla (2005). This research was conducted based on a documentary analysis in official documents of government programs. In addition, an electronic form was prepared and sent to two teachers from two public schools involved in these proposals. The results show that the programs under study contributed to interdisciplinary practices, so the immersion of digital technologies from an interdisciplinary perspective is done following the school's curriculum proposal, since policies are re-signified by social subjects who translate political texts in different arenas. The results show that the program proposals are conducive to the development of interdisciplinary practices, however, the gaps felt by teachers in the context of practice, echo as an unfavorable factor for the immersion of digital technologies from an interdisciplinary perspective.

Keywords: Public POLICY; INTERdisciplinary CURRICUlum; Digital INCLUSION.

Resumen Este trabajo propone analizar las políticas de tecnología educativa Programa Nacional de Tecnología Educacional - PROINFO (Programa Nacional de Tecnología Educativa) y Programa um Computador por Aluno - PROUCA (Programa Una Computadora por Alumno) en un diálogo interdisciplinar. Para estudiar los programas como una política, Ball y Bowe (1998) se utilizan como referencia cuando se discute el ciclo de las políticas. Se discute la interdisciplinariedad como relación pedagógica y dialógica a partir de Fazenda (2008) en colaboración con Souza y Fazenda (2017) que relacionan tecnologías, currículo e interdisciplinariedad. Pereira (2006) y Bonilla (2005) contemplan la discusión sobre la inclusión digital como un proceso de apropiación de las tecnologías digitales de forma activa, participativa y propositiva. Esta investigación se realizó a partir de un análisis documental en documentos oficiales de programas gubernamentales. Además, se elaboró un formulario electrónico y se les envió a dos docentes de dos escuelas públicas involucradas en estas propuestas. Los resultados muestran que los dos programas propuestos parecen propiciar el desarrollo de prácticas interdisciplinarias, sin embargo, como deficiencias que se sienten en la enseñanza del cabello sin un contexto práctico, lo hacen eco como factor desventajoso en la inmersión de las tecnologías digitales en una perspectiva interdisciplinar.

Palabras Clave: Políticas públicas; Plan de estudios interdisciplinario; Inclusión Digital.

\section{INTRODUÇÃo}

Com o desenvolvimento crescente da informática e da acelerada expansão da internet, surgem novas formas de comunicação, interação social, aprendizagem, disseminação de conteúdos e de culturas digitais. A primeira década do século XXI é impulsionada por transformações tecnológicas, dentre as quais está a utilização de dispositivos móveis co- 
nectado às redes, como celular, tablet e notebook. Esses artefatos permitem utilização desprendida de lugares fixos e que utiliza diferentes linguagens e novos processos sociotécnicos (LUCENA, 2016), assim, as tecnologias digitais nos permitem estar conectados no trabalho, na escola, no lazer, modificando significativamente a nossa relação com o mundo.

No contexto educacional, a efervescência do uso das tecnologias digitais tem adentrado no âmbito escolar pelas mãos dos alunos, nomeados por Michel Serres de Geração Polegarzinha:

\begin{abstract}
Essas crianças, então, habitam o virtual. As ciências cognitivas mostram que o uso da internet, a leitura ou a escrita de mensagem com o polegar, a consulta a Wikipédia ou ao Facebook não ativam os mesmos neurônios nem as mesmas zonas corticais que o uso do livro, do quadro negro ou do caderno. Essas crianças podem manipular várias informações ao mesmo tempo. Não conhecem, não integralizam nem sistematizam da mesma forma que nós, seus antepassados (SERRES, 2013, p. 19).
\end{abstract}

Atentos a esses novos sujeitos, educadores e especialistas da educação começam a buscar alternativas para atender as necessidades e interesses dos alunos das instituições escolares. Partindo dessa prerrogativa, o Governo Federal propôs o Programa Nacional de Tecnologia Educacional - PROINFO (1997) e o Programa um Computador por Aluno PROUCA (2010). Tais políticas educacionais foram apresentadas com o intuito de inserir as tecnologias digitais no espaço escolar.

Vale ressaltar que os programas PROINFO e PROUCA são considerados como políticas educacionais, pois são propostas governamentais de fomento ao uso pedagógico da tecnologia digital nas escolas. Compreende-se a política relacionada com o fazer e o pensar, com os meios em que antecedem a chegada ou a ausência desses artefatos tecnológicos nas escolas, e ainda, com os usos no contexto digital. Desse modo, "políticas educacionais são produções de significações curriculares desenvolvidas em múltiplos contextos" (SANTOS, 2016, p. 216). Dito isso, o conjunto de ações no qual visa integrar as tecnologias no currículo escolar se configura como política. Baseado nessa perspectiva, nos referimos aos programas, objeto desse estudo, como políticas de tecnologias educacionais.

Ademais, concorda-se com Souza e Fazenda (2017) que as tecnologias compõem novas formas de interações, tanto com os sujeitos quanto com o conhecimento. A utilização desses artefatos requer pensar práticas dialógicas entre professor e aluno frente à realidade que nos cerca. Sobre a ideia de prática, Fernandes expressa:

[...] prática intencional de ensino e aprendizagem não reduzida à questão didática ou às metodologias de estudar e de aprender, mas articulada à educação como prática social e ao conhecimento como produção histórica e social, datada e situada, numa relação dialética entre prática-teoria, conteúdo-forma e perspectivas interdisciplinares (FERNANDES, 1999, p. 159 apud VERDUM, 2013, p. 94).

A prática ultrapassa interpretações do fazer para ensinar. A escola situada em seu tempo e espaço dispõe de elementos relacionados entre si, uma vez que nela transitam histórias, sujeitos sociais, diferentes saberes que contribuem com o conhecimento construído. 
Nesse contexto, práticas de ensino interdisciplinar tornam-se necessária. Para Fazenda (2011), a interdisciplinaridade se configura como "nova atitude diante da questão do conhecimento, de abertura à compreensão de aspectos ocultos do ato de aprender e dos aparentemente expressos" (p. 11), ou seja, nova postura frente aos saberes construídos historicamente, onde o diálogo entre os campos do saber estabelece como uma relação mútua.

A nossa pesquisa apresenta a seguinte questão central: Como as propostas do PROINFO e do PROUCA, tidas nesse estudo como políticas de tecnologias educacionais, colaboram com o desenvolvimento de práticas curriculares de ensino interdisciplinar? Com isso, definimos, como objetivo geral, analisar como as propostas dos programas governamentais PROUCA e PROINFO colaboram com práticas curriculares de ensino interdisciplinar.

A pesquisa é qualitativa mediante a análise documental em documentos oficiais dos programas PROINFO (1997/2007) e PROUCA (2010). As buscas foram realizadas no site do Ministério da Educação - MEC e do Fundo Nacional de Desenvolvimento da Educação - FNDE. Além disso, utilizou-se como metodologia o formulário eletrônico do Google Forms, um dos aplicativos do Google Drive. Esse formulário pode ser disponibilizado através de um endereço eletrônico e, quando preenchido pelos respondentes, as respostas aparecem imediatamente na página do Google Forms do usuário que os criou (MATHIAS; SAKAI, 2013, p. 1). O nosso formulário foi elaborado com perguntas abertas direcionado a três professores que atuam as propostas de tais políticas, sendo dois participantes do PROINFO e outro do PROUCA.

Os docentes participantes lecionam em instituições diferentes, ambas pertencentes a rede estadual de ensino do Rio Grande do Norte e situadas no município de Natal. Referenciaremos as escolas lócus da pesquisa: Escola Net e Escola Web ${ }^{1}$. A Escola Net é de médio porte, possui turmas enquadradas na proposta do novo Ensino Médio que funcionam no horário matutino e vespertino, e Ensino Médio Diferenciado funcionando no período noturno, com 826 alunos matriculados. O PROINFO foi implantado na Escola Net em 2008. Já a Escola Web, funciona nos três turnos ofertando o Ensino Médio em Tempo Integral. Atualmente, 760 alunos estão matriculados, sendo estes do próprio bairro e do entorno. $\mathrm{O}$ PROUCA chegou na instituição em 2011.

Quanto aos três docentes participantes da pesquisa, os nomeamos de F1, F2 e F3². O professor F1 concluiu sua graduação em geografia em 2009 e atua há 10 anos na educação básica. O professor F2 formou-se em língua portuguesa no ano de 2002 e leciona há 16 anos em escolas de educação básica. Já o professor F3 é graduado em Química, concluiu o curso superior em 2006 e atua na educação básica há 10 anos.

Com o intuito de buscar informações nos documentos, analisaremos como essas políticas têm sido estruturadas e propostas. Além disso, compreender o processo de constituição e releituras dos programas através das afirmações dos docentes nos dará subsídio para percebermos as suas ressignificações no contexto da prática.

Para assegurar o anonimato das instituições participantes da pesquisa as identificaremos através dos seguintes nomes fictícios: Escola Net e Escola Web, conforme afirmamos. A escola NET é a instituição beneficiada pelo PROINFO, enquanto a escola Web pelo PROUCA.

2 Para assegurar o anonimato dos professores participantes da pesquisa os identificaremos através dos nomes fictícios F1, F2 e F3. 
Os textos políticos serão consultados, ou seja, no contexto da produção de texto (BALL; BOWE, 1992) em busca de analisar a proposta de utilização das tecnologias digitais nos referidos documentos. Ressalta-se que os textos oficiais não são considerados como políticas únicas ou maiores, pois a sua ressignificação no contexto da prática apresenta-se também como política. Segundo Ball e Bowe (BOWE et al., 1992), o contexto da prática é onde a política é interpretada e recriada, provocando mudanças e transformações significativas na política escrita.

Para entender os programas como política, utiliza-se como referencial Ball e Bowe (1998) quando discutem o ciclo de políticas mediante o contexto da influência, contexto da produção de texto e contexto da prática. Entendendo práticas como processos curriculares, Lopes e Macedo (2014) subsidiará a discussão de currículo como prática discursiva. A interdisciplinaridade na perspectiva de relação pedagógica dialógica será discorrida a partir de Fazenda (2008) em colaboração ainda com Souza e Fazenda (2017), que relacionam as tecnologias, currículo e interdisciplinaridade. Sobre os desafios da escola frente ao contexto digital em rede, adentra-se nos estudos de Santos (2005). A discussão sobre inclusão digital como processo de apropriação das tecnologias digitais de forma ativa, participativa e propositiva, será contemplada por Pereira (2006) e Bonilla (2005).

Esse trabalho será discorrido seguindo quatro eixos principais. Como discussão introdutória procuraremos discorrer acerca da escola diante do contexto do digital em rede, trazendo como foco principal os desafios advindos desse cenário. Posteriormente, procuraremos apresentar as propostas dos programas PROINFO e PROUCA trazendo os decretos, leis e diretrizes que regem essas políticas. Paralela a essa discussão, discorreremos sobre os referidos programas e sua potencialização para práticas de ensino interdisciplinar. Por fim, buscaremos compreender a partir das percepções e experiências dos docentes as políticas de tecnologias digitais ressignificadas no contexto da prática.

\section{OS DESAFIOS DA ESCOLA FRENTE AO CONTEXTO DO DIGITAL EM REDE}

As tecnologias da informação e comunicação potencializadas pelos seus diferentes artefatos têm adentrado nos espaços sociais, impactando significativamente em mudanças comportamentais e interacionais. Segundo Santos:

\footnotetext{
As redes, não só de máquinas e de informação, mas principalmente de pessoas, tribos e comunidades, estão permitindo configurar novos espaços de interação e de aprendizagem. Tais possibilidades estão pondo em xeque o papel e o "poder centralizador" dos professores na contemporaneidade (SANTOS, 2005, p. 18).
}

Nesse sentido, o papel do professor ultrapassa a prerrogativa de único detentor do conhecimento, pois as informações circulam em todo tempo e espaço e podem ser manipulados desde que tenhamos posse de dispositivos como: celular, tablet, notebook ou computador com acesso à internet.

O processo educativo offline, ou seja, aquele que desconsidera as tecnologias digitais e suas possibilidades inerentes, tornou-se desestimulante e até mesmo desafiador. No âmbito escolar, a utilização de artefatos como o computador incide como uma exigência 
necessária, segundo Bongiovani e Araújo (2013, p. 2) “é importante agregar a informática ao currículo escolar, pois os computadores estão presentes na vida de alunos e professores, e à escola, cabe o dever de propiciar ao aluno as aprendizagens por meio das novas tecnologias". Para Santos (2005, p. 9), o computador se configura como "um objeto antropológico, pois permite que novas formas de pensar sejam instituídas. Um elemento que lida com linguagem permite que novas representações, novos processos de aprendizagem e de desenvolvimento cognitivo, possam emergir dessa interação sociotécnica”.

Sabendo disso, o computador e os demais recursos tecnológicos são grandes potencializadores de diferentes formas de ensinar-aprender, pois propiciam elementos fundamentais para o desenvolvimento de capacidades como: autonomia, autoria, criticidade e, consequentemente, postura emancipatória, tão necessária na contemporaneidade.

Partindo dessa premissa, na tessitura do currículo escolar, se faz necessário considerar as outras redes que favorecem aprendizagens significativas. Jucieude salienta que:

\begin{abstract}
No mundo contemporâneo, as fontes de informação, de instrução, e os meios de socialização se multiplicaram. O sujeito circula e interage em diversos espaços de socialização a partir dos quais constrói referências para perceber e agir no mundo, portanto, é inevitável que, através dos sujeitos, esses espaços sejam permeáveis e atravessados por outras formas e possibilidades de desenvolver o pensamento (JUCIEUDE et al, 2005, p. 4).
\end{abstract}

A concepção de um currículo que envolva as diferentes necessidades dos sujeitos e suas teias de aprendizagem tem se estabelecido como um desafio a ser superado no cenário da escola. Cabe ressaltar que, ao contrário do rádio, tv, jornal impresso e revistas, a utilização das tecnologias digitais ultrapassa a ideia de apenas distribuição de informações, na qual não permite intervenção e interação direta entre emissor e receptor.

No contexto educacional brasileiro, políticas educacionais foram pensadas, estruturadas e implementadas a fim de incentivar a imersão das tecnologias digitais no processo educativo, desse modo, projetos, programas, bem como, leis e decretos, buscam levar às escolas artefatos tecnológicos na perspectiva de integrá-los ao processo de ensino-aprendizagem. Na discussão a seguir, procuraremos apresentar PROUCA e o PROINFO. Cabe ressaltar que as referidas políticas são consideradas as principais no que se refere a imersão das TIC na Educação Básica do país.

\title{
OS PROGRAMAS GOVERNAMENTAIS PROINFO E PROUCA: A IMERSÃo DOS DISPOSITIVOS TECNOLÓGICOS NA EDUCAÇÃO BÁSICA
}

O PROINFO se constitui como um dos principais programas governamentais que visa levar as tecnologias digitais para as escolas públicas do país. Criado através da Portaria ${ }^{\circ}$ 522 de 9 de abril de 1997, sua proposta inicial pautava-se em:

Art. $1^{\circ}$ Fica criado o Programa Nacional de Informática na Educação - Proinfo, com a finalidade de disseminar o uso pedagógico das tecnologias de informática e telecomunicações nas escolas públicas de ensino fundamental e médio pertencentes às redes estadual e municipal (Brasil. MEC, 1997, p. 1). 
A partir do programa, laboratórios de informática foram instalados nas escolas. Cabe ressaltar que, em 2007, o programa foi reformulado e passou a denominar-se de Programa Nacional de Tecnologia Educacional, com seu foco principal na utilização pedagógica dos recursos tecnológicos na educação básica. Foram criados nos estados e municípios, os Núcleos de Tecnologia Educacional - NTE e NTM, onde atuam profissionais da educação e especialistas em hardware e software responsáveis pela formação dos educadores para utilização das TIC (CORDEIRO; BONILLA, 2018. p. 5).

A home page do MEC - Ministério da Educação - informa que o programa leva às escolas computadores, recursos digitais e conteúdos educacionais. Em contrapartida, estados, Distrito Federal e municípios devem garantir a estrutura adequada para receber os laboratórios e capacitar os educadores para uso das máquinas e tecnologias.

Segundo o documento de Diretrizes, são objetivos do PROINFO:

\begin{abstract}
Melhorar a qualidade do processo de ensino-aprendizagem através da igualdade de acesso a instrumentos tecnológicos disponibilizadores e gerenciadores de informação;

Possibilitar a criação de uma nova ecologia cognitiva nos ambientes escolares mediante incorporação adequada das novas tecnologias da informação pelas escolas aproximando a cultura escolar da cultura extra-escolar;

Propiciar uma educação voltada para o desenvolvimento científico e tecnológico a fim desenvolver a intuição, criatividade, agilidade de raciocínio associada ao manejo da tecnologia e maior conhecimento técnico;

Educar para uma cidadania global numa sociedade tecnologicamente desenvolvida, capazes de se comunicar, conviver e dialogar num mundo interativo e interdependente (BRASIL, 1997, p. 3).
\end{abstract}

O documento ainda pontua que

É preciso diminuir a lacuna existente entre a cultura escolar e o mundo ao seu redor, aproximar a escola da vida, expandindo-a em direção à comunidade e tornando-a facilitadora das interações entre os atores humanos, biológicos e técnicos (BRASIL, 1997, p. 3).

Dito isso, cabe à escola, enquanto participante ativa das transformações culturais de uma sociedade, promover a criação de ambientes educacionais que favoreçam a construção de aprendizagens mediada pelas novas tecnologias da informação.

Outra política do Governo Federal que visa a inclusão digital no cenário escolar foi o Programa Um Computador Por Aluno - PROUCA - instaurado pela Lei $\mathrm{n}^{\circ} 12.249$ de 10 de junho de 2010, que tem por objetivo promover a inclusão digital pedagógica e o desenvolvimento dos processos de ensino e aprendizagem de alunos e professores das escolas públicas brasileiras, mediante a utilização de computadores portáteis denominados laptops educacionais (MINISTÉRIO DA EDUCAÇÃO, 2010). Vale ressaltar que antes de ser instituído como programa, este foi instaurado como projeto UCA, proposto no Brasil em 2005, pelo governo do presidente Luiz Inácio Lula Da Silva, e criado através do decreto $\mathrm{n}^{\mathrm{o}}$ 6.300, de 12 de dezembro de 2007 (BRASIL, 2007). "O Projeto UCA, por sua vez, caracterizou-se pela distribuição de laptops educacionais a aproximadamente 300 escolas 
públicas, de ensino fundamental e médio, em zonas rurais e urbanas em todas as regiões do país" (CORDEIRO; BONILLA, 2018. p. 7).

O FNDE afirma em sua home page que o PROUCA foi implantado com o objetivo de intensificar as tecnologias da informação e da comunicação nas escolas por meio da distribuição de computadores portáteis aos alunos da rede pública de ensino. Foi um projeto que complementou as ações do MEC referentes às tecnologias na educação, em especial os laboratórios de informática, produção e disponibilização de objetivos educacionais na internet dentro do PROINFO integrado.

No que se refere ao PROUCA, segundo o FNDE, o equipamento adquirido contém sistema operacional específico e características físicas que facilitam o uso e garantem a segurança dos estudantes e foi desenvolvido especialmente para uso no ambiente escolar. Todavia, o programa foi extinto e as prefeituras interessadas precisam fazer adesão ao PROINFO.

Assim como nas propostas dos programas objeto desse estudo, o termo inclusão digital tem sido fortemente propagado em diferentes políticas e ações nas mais diversas instituições da sociedade contemporânea. Bonilla (2005), a partir de uma análise crítica e construtiva, instiga a compreender a leitura social associada ao termo. Para a autora, a inclusão digital ultrapassa a condição de sujeito consumidor de instrumentos tecnológicos. Desse modo, estar incluído digitalmente significa "oportunizar condições para que os sujeitos sejam capazes de participar, questionar, produzir, decidir, transformar, tornando-se parte integrante da dinâmica social, em todas as suas instâncias" (BONILLA, 2005, p. 43).

Em suma, os programas PROINFO e PROUCA inseriram no âmbito da escola pública dispositivos tecnológicos que favorecem o diálogo com as atuais dinâmicas sociais. Todavia, ao implementar uma política, é necessário fornecer suporte para a sua eficiência. Aspectos como formação docente, infraestrutura, suporte técnico, precisam ser considerados, dessa forma, caminhará para uma proposta que favoreça a inclusão digital e ainda uma proposta curricular interativa, colaborativa e interdisciplinar. Na próxima sessão desse estudo, buscaremos discorrer sobre as políticas apresentadas anteriormente, com ênfase nos dispositivos tecnológicos oferecidos, para, assim, analisarmos suas contribuições na promoção de práticas de ensino interdisciplinar.

\section{DO COMPUTADOR AO LAPTOP: AS POLÍTICAS DE TECNOLOGIAS EDUCACIONAIS POTENCIALIZANDO PRÁTICAS DE ENSINO INTERDISCIPLINAR}

A interdisciplinaridade surgiu nas ciências humanas a partir de um projeto estruturado pela Organização das Nações Unidas para Educação, Ciência e Cultura - UNESCO, onde buscava a unicidade dos conhecimentos e a superação de sua natureza fragmentária e reducionista (MORAES, 2008 apud MOREIRA, 2003).

Segundo Yared (2008), como a própria palavra indica, interdisciplinaridade não é um conceito fechado em si mesmo, pois, desta forma, já não seria inter = movimento. A interdisciplinaridade tem sido atrelada/limitada ao sentido epistemológico da relação entre as disciplinas. Todavia, Fazenda (2008, p. 180) afirma que "a interdisciplinaridade se pauta numa ação em movimento. Pode-se perceber esse movimento em sua natureza ambígua, tendo como pressuposto a metamorfose, a incerteza". 
A atitude interdisciplinar requer verdadeiro e profundo diálogo entre os campos de saber com espaço para uma relação colaborativa, desse modo, os conhecimentos compartimentados através das disciplinas não permitem estabelecer o diálogo, uma vez que, se cada disciplina está engessada em seus conhecimentos, a aproximação torna-se uma tarefa complexa. Japiassu (1976 e 2006 apud FAZENDA, 2008, p. 24) aponta o diálogo como crucial numa prática educativa: "é preciso que todos estejam abertos ao diálogo, que sejam capazes de reconhecer aquilo que lhes falta e que podem ou devem receber dos outros".

Vale ressaltar que a interdisciplinaridade proposta no currículo escolar se materializa na prática docente, no planejamento de ações (MORAES, 2008 apud MOREIRA, 2003). Nesse sentido, Tavares nos faz refletir sobre os tempos de múltiplas possibilidades em que emerge a necessidade de agir/pensar interdisciplinarmente, ainda mais no mundo dominado pelas tecnologias.

Um tempo no qual somos convidados a pensar em outras possibilidades, rever
antigos conceitos e concepções com um olhar que acolha múltiplas perspectivas
e rejeite as explicações únicas ou as verdades universais que até agora nortea-
ram nosso entendimento. É fato que a humanidade vive um momento histórico
sem precedentes. A tecnologia diminuiu de tal forma as distâncias e o tempo
que já não é figura de linguagem dizer que o mundo é uma pequena aldeia
(TAVARES, 2011, p. 69).

A interligação entre as tecnologias e as práticas de ensino interdisciplinar tona-se necessária a medida em que os diversos conhecimentos são encontrados, manipulados e compartilhado entre todos nas redes. Tavares ainda afirma:

Utilizada e desenvolvida inicialmente para atender a atividade econômica, a tecnologia agora faz-se sentir em todas as atividades humanas. Culturas diferentes passaram a ter um convívio mais próximo, o que evidenciou a interdependência e, por outro lado, aumentou o desejo de competição e dominação. Muito desentendimento surgiu porque alguns querem que o mundo seja de uma única maneira, da sua maneira (TAVARES, 2011, p. 69).

Nesse contexto, a presença das TIC nos variados espaços sociais possibilitou convivência mútua entre diferentes culturas e, consequentemente, aproximação entre variados campos do saber, com isso, a exacerbada competição de validação de um único conhecimento para entender as questões da humanidade aumenta, todavia, não é possível a apreensão de sentido do mundo sob uma única ótica.

As políticas brasileiras PROINFO e PROUCA, nas quais visam a integração das tecnologias digitais (laptops e computadores) no currículo escolar, criam espaços para práticas de ensino interdisciplinar. Os variados recursos, como vídeos, áudios, jogos, softwares educativos, imagens, aplicativos, dentre tantos outros, potencializam o diálogo entre as áreas do conhecimento.

Sobre a ideia de currículo, Lopes e Macedo (2014, p. 41) definem: "o currículo, é ele mesmo, uma prática discursiva. Isso significa que ele é uma prática de poder, mas também uma prática de significação, de atribuição de sentidos". Nesse sentido, o currículo 
condiciona a nossa realidade, uma vez que nele está empregado discursos sobre a identidade, cultura, significações, representação, alteridade e relação de saber-poder (SOUZA; FAZENDA, 2017). Sabendo que as tecnologias digitais fazem parte de nossa vida cotidiana, Lopes e Macedo (2014), enfatizam a importância de considerar no currículo aspectos pertencentes às nossas vivencias externas Segundo as autoras (2014, p. 66), "currículos centrados nas histórias de vida dos sujeitos a partir das quais os 'conteúdos' curriculares se tornam existencialmente significativos".

A incorporação no currículo dos recursos disponibilizados pelas políticas governamentais objeto desse estudo precisa ser feita partindo da proposta curricular da escola. Nascimento propõe que o computador seja utilizado da seguinte forma:

\footnotetext{
Por disciplina: nessa modalidade, os professores utilizam os computadores como reforço, complementação ou sensibilização para os conteúdos abordados em sala de aula, em sua disciplina específica, de forma isolada.

Projetos educacionais: nesse enfoque, a utilização da informática acontece de forma integrada entre as várias disciplinas no desenvolvimento de propostas de projetos. O modo de utilização do ambiente de informática também é uma questão a ser discutida (NASCIMENTO, 2009, p. 38).
}

Nessa perspectiva, o autor coloca que a utilização da informática por meio de projetos educacionais permite maior articulação entre as várias disciplinas. Com base nisso, Fazenda (2006, p. 32 apud ALVES, 2013, p. 100) destaca que, na escola, há muitos professores que intuitivamente buscam a interdisciplinaridade, mas devido ao afastamento da academia e da teoria, terminam, consequentemente, realizando projetos multidisciplinares iludidos pelo senso comum de que são interdisciplinares.

A discussão sobre as tecnologias digitais propostas nas políticas educacionais e a interdisciplinaridade nos convoca a refletir sobre a utilização desses artefatos. Para D'Avila e Leal (2012, apud RIBEIRO, 2015, p. 53), "muitos usam as tecnologias cotidianamente fora do ambiente escolar, mas na prática pedagógica, o nexo não se estabelece. As tecnologias ainda são vistas numa perspectiva instrumental como recurso didático na sala de aula". Assim sendo, a utilização instrumental não incorpora todas as potencialidades que os artefatos tecnológicos possuem. É preciso ressignificar o uso, ou seja, pensar estratégias para que o aluno desenvolva competências para utilizar esses artefatos além do que a técnica lhe oferece.

Em estudo sobre o PROUCA, Echalar e Peixoto (2017) abordam a implantação do programa no Brasil e no Estado de Goiás, partindo de aspectos como inclusão digital no ambiente escolar. Os autores investigam o programa através de discussões sobre a estrutura da política PROUCA e relatam problemas e deficiências na sua infraestrutura e implantação, fatores que fortalecem as desigualdades sociais.

A pesquisa foi realizada em nove escolas contempladas pelo programa em Goiás. Para tanto, as autoras se apropriam de uma análise documental com o intuito de perquirir os processos lógico-históricos entre a realidade aparente e a concreta realidade na implantação do PROUCA. Além disso, 55 profissionais foram entrevistados (ECHALAR; PEIXOTO, 2017). 
Segundo as autoras, o programa "renova a utopia técnica de que a sociedade evolui qualitativamente com a aquisição de tecnologias de informação e de comunicação" (ECHALAR; PEIXOTO, 2017, p. 408). Tal constatação é expressa através de alguns aspectos, a saber: problemas e deficiência na infraestrutura para a implantação do programa, na gestão de processos e na formação de professores. O trabalho aponta a lógica econômica como determinante para a implantação dos programas e ainda frisam que:

O Estado, ao fazer concessões e parcerias com os organismos internacionais, imputa ao docente um modo de pensar e agir baseado nas leis do mercado e do capital. Esta racionalidade se fundamenta muito mais na lógica do resultado e na reprodução de normas e leis do que no desenvolvimento intelectual autônomo (ECHALAR; PEIXOTO, 2017, p. 407).

Concorda-se que a lógica econômica, assim como social e política, influencia e direciona a implementação de programas como o PROUCA, todavia, não condiciona. Para os autores, o Estado, através de suas parcerias com organismos internacionais, enquadra o modo de pensar e agir dos docentes no padrão do mercado e do capital. Diferentemente dos autores, entendemos, a partir de Ball (1992), que professores e gestores, enquanto sujeitos imbuídos de saberes/fazeres, colaboraram com a ressignificação de políticas, uma vez que, a escola constrói os seus próprios sentidos e significados acerca das políticas, e mais, tece no cotidiano a sua própria política alicerçada nas propostas do Estado. Dessa forma, a imersão das tecnologias no âmbito da escola é resultado de uma política criada não apenas pelos entes governamentais, mas também pela comunidade escolar ao interpretá-la.

Investigando a implantação do PROINFO em quatro escolas localizadas em Santa Catarina, Ronsani (2004) realizou seu estudo perseguindo quatro objetivos principais:

1) evidenciar o desenvolvimento das tecnologias de comunicação, destacando o seu potencial de transformação da organização do trabalho didático; 2) descrever o Programa Nacional de Informática na Educação (PROINFO) e o Programa de Informática do Estado de Santa Catarina; 3) caracterizar as instituições delimitadas na pesquisa e 4) discutir criticamente o programa, verificando o grau de consecução de seus objetivos e a adequação das medidas que mobilizam recursos materiais e humanos para a sua realização (RONSANI, 2004, p. 2).

Para atender as expectativas da pesquisa, a autora utilizou como técnicas de coleta de dados a observação dos equipamentos e das salas de informática; entrevistas semiestruturadas com 70 educadores incluindo professores, gestores, multiplicadores, responsáveis pelas salas de informática e pelo Núcleo de Tecnologia Educacional (NTE). Além disso, utilizou-se como técnica a análise documental através de consultas nos principais textos oficiais do PROINFO, no projeto político pedagógico de cada escola participante da pesquisa, no documento do estado de Santa Catarina que norteia as Políticas de Tecnologias da Informação e Comunicação para as escolas deste estado.

Em linhas gerais, nos debruçamos na pesquisa de Ronsani (2014) com o intuito de percebermos e compreendermos o desenvolvimento da política do PROINFO no âmbito 
das quatro escolas que fazem parte do estudo. Diante disso, a autora traz, através dos discursos dos sujeitos, elementos que nos revelam a política em ação (BOWE et al., 1992).

A primeira questão levantada tratou sobre a utilização das salas informatizadas - SI. Os dados evidenciam que de um universo de 55 professores entrevistados, apenas $9 \%$ faz uso frequente dos recursos disponíveis nesse espaço, enquanto 64\% não os utilizam em suas atividades. Os docentes assíduos na SI relatam que apesar de dificuldades como a quantidade insuficiente de computadores para atender toda turma, o investimento em atividades nesse espaço apresenta resultados, pois o computador desperta nos alunos interesse e curiosidade. Os docentes que não fazem tal uso alegam pouca ou ausência de preparação, tempo reduzido, precariedade das máquinas, ausência de materiais como tinta nas impressoras, possuir computador em casa e ainda pouca clareza quanto aos objetivos da informática em sua prática de ensino (RONSANI, 2014).

Sob essa perspectiva, recorremos a Sousa (2014) que, analisando os escritos de Ball e colaboradores (1992) sobre o ciclo de políticas e a teoria da atuação, nos mostra que a política, ao ser lida e interpretada por diferentes sujeitos, os efeitos que ela causará tornam-se incontrolável pelos seus implementadores. Vejamos:

\footnotetext{
Nessa abordagem do ciclo de políticas, em conjunto com a teoria da atuação, fica difícil prever os efeitos de uma política, porque não se relacionam apenas à capacidade de controle por seus formuladores. Nesse ponto, todos os atores envolvidos "no fazer da política", no "colocá-las em práticas", podem efetivar as suas interpretações (rejeitando, anulando, aceitando parcialmente, etc.). Essas interpretações resultam de histórias, de interesses, de valores etc., que cada ator político carrega dentro de si, ou seja, existe uma subjetividade da política, que não pode ser controlada, por mais que se deseje (SOUSA, 2014, p. 9).
}

Dito isso, quando analisamos os discursos dos professores participantes da pesquisa de Ronsani (2014) fica evidente as diversas posições políticas tomadas por tais atores frente a atuação de uma mesma política, o PROINFO. Enquanto uns enxergam relevância, outros são contrários ou parcialmente favoráveis a essa política, e isso reverbera no modo como a política é colocada em ação nas escolas.

Com relação à aceitação dos professores a política do PROINFO, Castro (2011, p. 106) destaca que "tratando-se de uma política em implementação, cujo desenvolvimento depende tão drasticamente da adesão do professor - conforme expressa o próprio texto da política - a formação passaria, também, pela prática da participação política desses professores". Sendo assim, a formação de professores no processo de imersão das tecnologias digitais no âmbito escolar torna-se essencial para considerável adesão de uma política que depende da participação do corpo docente para ser atuada. Sobre essa questão, discorreremos mais à frente.

Cabe ressaltar que as questões apresentadas pelo estudo supracitado são contraditórias com aquilo que consta no texto da política dos programas. O Decreto $\mathrm{n}^{\mathrm{o}} 6.300$, de 12 de dezembro de 2007, no qual dispõe sobre o PROINFO, propõe:

Uso pedagógico das tecnologias de informação e comunicação nas escolas, contribuir com a inclusão digital por meio da ampliação do acesso a compu- 
tadores, capacitação dos professores e dos outros agentes educacionais para a utilização pedagógica das TIC, suporte técnico e manutenção dos equipamentos do ambiente tecnológico do Programa, recursos humanos e condições necessárias ao trabalho de equipes de apoio para o desenvolvimento e acompanhamento das ações de capacitação nas escolas (BRASIL, 2007).

Frente a essa realidade, recorremos a Mainardes (2006), que, inspirado em Ball e Bowe (1992), aborda os três contextos para analisar a trajetória das políticas educacionais brasileiras, sendo estes: o contexto de influência, o contexto da produção de texto e o contexto da prática. De acordo com o autor, tais contextos estão interligados e nenhum destes sobressai ao outro, não existe assim uma linearidade. É no contexto da influência que normalmente as políticas públicas são iniciadas e os discursos políticos são construídos. É a partir do contexto da produção de texto que os textos políticos são elaborados, portanto, representam a política. Já o contexto da prática permite que a política esteja sujeita à interpretação e recriação e onde a política produz efeitos e consequências que podem representar mudanças e transformações significativas na política original.

A análise dos programas PROUCA e PROINFO com base na literatura redigida pelos implementadores: leis, diretrizes, decretos, documentos do MEC (contexto da produção de texto) e em sua implantação nas escolas a partir dos estudos Echalar e Peixoto (2017) e Ronsani (2004), sob a ótica do contexto da prática, nos revelam pontos divergentes em alguns aspectos, pois ao mesmo tempo que há garantias expressas no texto político (infraestrutura, formação de professores), existem lacunas e fragilidades quanto a esses aspectos. Tais constatações são evidenciadas nos diferentes discursos. Ball também nos ensina que:

As políticas normalmente não nos dizem o que fazer, elas criam circunstâncias nas quais o espectro de opções disponíveis sobre o que fazer é reduzido ou modificado ou nas quais metas particulares ou efeitos são estabelecidos. Uma resposta ainda precisa ser construída no contexto, contraposta ou balanceada por outras expectativas. Tudo isso envolve algum tipo de ação social criativa (BALL, 2006, p. 26, apud SCHUCHTER, 2017, p. 77).

Partindo desse pressuposto, o uso das tecnologias, através das políticas, é incorporado de acordo com as concepções e práticas curriculares assumidas pela escola. A interdisciplinaridade, assim como as TIC, como podemos contatar ao longo desse estudo, é tida como postura implicada com a realidade. Para Souza e Fazenda (2014), quando a escola assume a sua natureza ideológica, seu posicionamento acerca daquilo que compreende ser seu papel social e como o coloca em prática no cotidiano, todos que nela trabalham, se envolvem e assumem seu papel de forma coerente e intencional.

Ferreira nos convoca a pensar sobre as configurações de uma prática interdisciplinar ao afirmar:

O que caracteriza uma prática interdisciplinar é o sentimento intencional que ela carrega. Não há interdisciplinaridade se não há intenção consciente, clara e objetiva por partes daqueles que a praticam. Não havendo intenção de um projeto, podemos dialogar, inter-relacionar e integrar sem, no entanto, estarmos trabalhando interdisciplinarmente (FERREIRA, 1993, p. 34). 
Diante disso, a escola é convocada a pensar em estratégias que ultrapassem o conhecimento compartimentado das disciplinas. Isso requer propostas pedagógicas intencionais, objetivas, direcionadas e implicadas. As políticas de tecnologias educacionais inseriram dispositivos tecnológicos com objetivo de utilização pedagógica. Tais artefatos são muitas vezes utilizados pelos alunos para busca de informação e conhecimento que não estão compartimentados em disciplinas, ou seja, os conteúdos encontrados nas redes são essencialmente indisciplinar. Diante disso, programas como o PROUCA e o PROINFO podem contribuir com a efetivação de práticas interdisciplinares por oferecerem o uso de artefatos potencializadores de aprendizagens dialogadas e colaborativas entre os variados campos do conhecimento.

Na próxima sessão desse estudo, buscaremos apresentar a ressignificação das políticas de tecnologias digitais no contexto nomeado por Bowe, Ball e Gold (1992) de contexto da prática. Para tanto, selecionamos três docentes que atuam tais propostas para expressarem suas experiências e percepções.

\title{
AS POLÍTICAS DE TECNOLOGIAS DIGITAIS RESSIGNIFICADAS NO CONTEXTO DA PRÁTICA
}

Para iniciarmos a discussão, cabe retomarmos as diferentes características apresentadas no contexto nomeado por Richard Bowe, Stephen Ball e Anne Gold (1992) de contexto da prática, para assim compreendermos a partir das concepções docentes a ressignificação das políticas do PROINFO e do PROUCA no âmbito das escolas. Na abordagem do ciclo de políticas, os autores nos instigam a percebermos a complexidade no ato de análise das políticas educacionais, para tanto, foram constituídos contextos, como já mencionados anteriormente, a saber: o contexto de influência, contexto da produção de texto, o contexto da prática. Cada um desses contextos apresenta arenas, lugares e grupos de interesse, envolvidos por disputas e embates (BOWE et al., 1992).

Para Bowe et al:

\begin{abstract}
Os profissionais que atuam no contexto da prática [escolas, por exemplo] não enfrentam os textos políticos como leitores ingênuos. Eles vêm com suas histórias, experiências, valores e propósitos [...]. A questão é que os autores dos textos políticos não podem controlar os significados de seus textos. [...] Interpretação é uma questão de disputas (BOWE et al, 1992, p. 22, apud MAINARDES, 2006, p. 53).
\end{abstract}

Nessa tessitura, vários sujeitos vão delineando a urdidura das ações, leituras e interpretações dos textos políticos. Desse modo, concordamos com Ball (2016, p. 14) ao afirmar que “esses textos não podem ser simplesmente implementados. Eles têm de ser traduzidos a partir do texto para a ação - colocados em prática - em relação à história e ao contexto, com os recursos disponíveis", uma vez que cada espaço onde a política precisa ser alcançada, possui seus próprios interesses, demandas e perspectivas que não cabem ser negligenciadas.

Partindo dessa premissa, entender como as políticas de tecnologias educacionais contribuem com o processo de ensino interdisciplinar nos convoca a perceber múltiplos senti- 
dos atribuídos por aqueles que exercem na política, por intermédio do contexto da prática, um papel ativo no processo interpretativo e reinterpretativo das propostas de governo. Sendo assim, a seguir, iremos apresentar falas de três docentes imbricadas com as discussões discorridas até o momento desse estudo.

As políticas dos programas, objeto desse estudo, propuseram levar às escolas recursos digitais para fomentar o desenvolvimento de práticas de ensino dialogadas com o uso das tecnologias da informação e comunicação. Para Pereira (2017, p. 13) no contexto atual, o grande desafio da sociedade civil é a exclusão digital, ou o analfabetismo digital. Frente a essa realidade, procuramos entender, através das respostas dos professores, em que medida os programas se constituíram como instrumento de inclusão digital e de apoio pedagógico no âmbito escolar. Assim responde o professor F1:

A proposta do PROINFO é excelente, pois levar o aluno a ter contato com ferramentas com tantas possibilidades traz para o processo de aprendizagem estímulos e criatividade diferentes daqueles que ficam presos apenas no quadro e livro. Mas entendo que esse programa não conseguiu atingir a inclusão digital por não haver ações pedagógicas direcionadas. Com isso, o programa vem perdendo espaço nas escolas.

A relevância da proposta do PROINFO é marcada na resposta do professor F1. No entanto, ele afirma que a carência de ações pedagógica direcionadas afetaram a proposta do programa, dessa forma, não se constituindo como uma política que possibilitou a inclusão digital de professores, alunos e demais membros da comunidade escolar.

Segundo Pereira, a inclusão digital configura-se como:

Um processo em que uma pessoa ou grupo de pessoas passa a participar dos
métodos de processamento, transferência e armazenamento de informações que
já são do uso e do costume de outro grupo, passando a ter os mesmos direitos
e deveres dos já participantes daquele grupo onde está se incluindo. Para isso,
precisamos dominar a tecnologia da informação, estou me referindo a com-
putadores, softwares, internet, correio eletrônico, serviços etc., que vão muito
além de aprender a digitar, conhecer o significado de cada tecla do teclado ou
usar o mouse. Precisamos dominar a tecnologia, para que, além de buscarmos a
informação, sejamos capazes de extrair conhecimento (PEREIRA, 2017, p. 17).

Nesse sentido, muito além da imersão dos dispositivos tecnológicos nas escolas, para que os sujeitos estejam digitalmente incluídos, se faz necessário o desenvolvimento de competências além do seu uso técnico e instrumental. Vale ressaltar que, no documento oficial do PROINFO, as discussões sobre inclusão digital não se constituíram como meta prioritária. Já nos seus moldes de criação em 1997, apenas dez anos mais tarde, quando o programa passa por reformulações, esta discussão entra em pauta.

Em diálogo com tal discussão, apresentamos a fala do Professor F2 ao relatar suas experiências atuando a proposta do PROINFO e suas apreensões ao tratar do processo de inclusão digital na escola: 
O PROINFO não obteve sucesso aquilo que entendo por inclusão digital. O fato de os computadores terem sido distribuídos nas escolas não é incluir a escola no mundo tecnológico. Mesmo com computadores a disposição sinto muitas dificuldades quando proponho usá-los com meus alunos; a conexão da internet é fraca, os computadores são lentos e com número insuficiente para atender a todos. Quando necessito usar, acabo sempre pensando em dois planos de aula, ou seja, um plano A e B, pois nem sempre a internet funciona ou todas as máquinas ligam. Para mim isso não tem nenhuma aproximação com a inclusão digital.

Atentos a essa fala, buscamos nos documentos oficiais do programa, ou seja, no contexto da produção de texto, entender como a inclusão digital é mencionada e tratada no texto político do PROINFO. O termo inclusão digital aparece no Decreto ${ }^{\circ} 6.300$ de 12 de dezembro de 2007 em parágrafo único como um de seus objetivos a serem atingidos, assim se encontra posto: São objetivos do PROINFO "IV - contribuir com a inclusão digital por meio da ampliação do acesso a computadores, da conexão à rede mundial de computadores e de outras tecnologias digitais, beneficiando a comunidade escolar e a população próxima às escolas".

Para incluir digitalmente as escolas e a população, o PROINFO aposta principalmente na ampliação da política de acesso às tecnologias. Estevão e Passos nos mostram que:

\begin{abstract}
A experiência, consoante avaliação realizada, mostrou uma grande evolução da presença de computadores nas escolas públicas brasileiras e um avanço na formação de recursos humanos para trabalhar com a tecnologia no processo educacional. No que concerne às metas e ao desenho operacional, foi exitosa, pois, segundo dados do MEC referentes ao período de 1996 a 2002, capacitou 137.911 professores, atendeu 6 milhões de alunos e instalou 53.895 computadores (ESTEVÃO; PASSOS, 2015, p. 201).
\end{abstract}

Pelo exposto, percebemos uma ampliação da presença das TIC nas escolas, todavia, o professor F2 ressalta que tal fato não garante concretizar a inclusão digital quando cita que fatores como conexão à internet, número e funcionamento dos computadores apresentam-se como entraves no que concerne a efetivação da inclusão digital na escola que leciona.

Chamamos atenção para as dificuldades elencadas pelo professor F2 ao destacar que o planejamento de aulas que requerem a utilização dos computadores do PROINFO é realizado seguido de um outro plano de aula, o que ele chama de "plano B", uma vez que nem sempre os artefatos funcionam como esperado. Tais ações se configuram como atuação, reinterpretação e reconfiguração da política, onde são definidas de acordo com o contexto em que é possível colocar a política em ação. Ball e seus colaboradores "concebem as políticas como um processo, como algo que se move, que acontece em meio a interações e em terrenos instáveis" (ROSA, 2019, p. 7 apud. SOUSA, 2019, p. 11). Desse modo, políticas estão sujeitas a transformações à medida que se encontram presentes em espaços instáveis e em corpos e ações de sujeitos que possuem seu próprio modo de ser, agir e pensar.

Analisando a fala do professor F3 sobre inclusão digital e o PROUCA, outra política de tecnologias que visou a distribuição de laptops educacionais para alunos e professores, este respondente observa que: 
O programa poderia ter contribuído de maneira mais significativa com a inclusão digital, mas com algumas fragilidades que percebemos ao ser implantado na escola prejudicou bastante seu andamento. Talvez tenha sido por isso que foi extinto. Na escola onde trabalho só os professores receberam os laptops. Os alunos foram contemplados apenas com pen drives e muitos nem se quer utilizavam. Lembro que cada professor utilizava os laptops de acordo com sua prática de ensino. Eu não tive oportunidade de participar de nenhum curso de formação para entender como eles deveriam serem utilizados. Apesar de tudo, o PROUCA foi um programa de apoio em nossas práticas pedagógicas, a medida nos deu suporte de criar planos de aula instigantes para os nossos alunos que estão a todo tempo navegando nas redes.

Assim como os discursos anteriores, o professor F3 também destaca que inclusão digital não foi alcançada dentro do cenário de uma política que tinha essa pretensão. Vejamos o que diz a Lei $n^{\circ} 12.249$ :

Art. $7^{\circ}$ - O PROUCA tem o objetivo de promover a inclusão digital nas escolas das redes públicas de ensino federal, estadual, distrital, municipal ou nas escolas sem fins lucrativos de atendimento a pessoas com deficiência, mediante a aquisição e a utilização de soluções de informática, constituídas de equipamentos de informática, de programas de computador (software) neles instalados e de suporte e assistência técnica necessários ao seu funcionamento (BRASIL, 2010).

A inclusão digital de alunos e professores apresenta-se explicitamente como um dos objetivos do PROUCA. Com base na fala do professor F3, é possível observar a realidade da política colocada em ação. O docente atribui o fato de a inclusão digital não ter se tornado uma realidade ao que ele nomeia de fragilidades, nas quais foram sentidas no cotidiano da escola (contexto da prática), a saber: distribuição desigual dos laptops, utilização desse recurso sem orientações direcionadas e ausência de cursos de formação.

Nesse cenário, reiteramos que os professores, enquanto atores das políticas, tomam suas posições ressignificando e performatizando o texto político, podemos constar esse fato analisando a fala do professor F3 ao afirmar que cada docente utilizava o artefato tecnológico seguindo suas perspectivas pedagógicas. Dito isso, Ball e Bowe (1992, apud MAINARDES, 2006) nos alertam que aquilo que professores e demais profissionais pensam e no que acreditam têm implicações para o processo de implementação das políticas.

Não podemos esquecer de analisar posições tomadas pelos alunos no cerne das políticas. Elmore destaca que:

Nós não deveríamos assumir que a política é a única influência sobre o comportamento dos professores. Os alunos também são atores das políticas. As respostas também são mediadas pelos sujeitos e pelas culturas de especialistas de vários tipos (ELMORE, 1996, apud BALL; MAGUIRE; BRAUN, 2016, p. 72).

Sabendo disso, a utilização dos pen drives ou não, se configura como atuação política dos alunos dessa escola, tendo em vista que estes são sujeitos, assim como demais membros da escola, imbuídos de interesses e aspirações. Partindo da ideia que defendemos e daquilo 
que entendemos por política, não há como desconsiderar a participação do alunado no fazer político das instituições escolares e até dos demais espaços que ele está inserido, como por exemplo a internet, espaço de criação e cocriação de inúmeras coisas assim como da política.

Visando entender as contribuições do PROINFO e PROUCA no desenvolvimento de práticas de ensino interdisciplinar, instigamos os docentes a relatarem suas experiências e impressões. De acordo com o Professor F1:

O programa pode contribuir com a interdisciplinaridade à medida que disponi-
bilizou salas de informática equipada com os computadores. Isso nos oferece
suporte para desenvolvermos atividades interdisciplinares, pela infinidade de
possibilidades de fazer relações com várias áreas de conhecimento.

Nesse sentido, o professor destaca que o PROINFO trouxe possibilidades de romper com as fronteiras disciplinares, tendo em vista as potencialidades de artefato que permitem criar/recriar diferentes metodologias de ensino interdisciplinar. Sob essa ótica, Araújo e Vilança (2016, p. 218) afirmam que "as tecnologias de informação e comunicação ampliaram as possibilidades de aprendizagem, possibilitando novos formatos, modalidades e ferramentas nos processos de ensino e aprendizagem". Nessa perspectiva, o professor F2 traz em sua fala uma pertinente reflexão sobre a política do PROINFO enquanto possibilidade de instigar no âmbito da escola práticas de ensino interdisciplinar, vejamos:

O PROINFO tem um grande potencial para fazer com que as escolas desenvolvam planos de ação, projetos e atividades interdisciplinares, pois trazer as tecnologias para dentro da escola oportuniza pensar as disciplinas fora de suas caixinhas, sem tantos fragmentos, basta saber como usá-las a favor disso. No entanto, pelas falhas que o programa tem, isso ainda precisa ser alcançado.

Analisando o discurso do docente, logo percebemos sua concepção sobre o conceito de interdisciplinaridade. Para este sujeito, o ensino interdisciplinar relaciona-se com a ideia de um conhecimento que rompe com as fronteiras das disciplinas, longe de compartimentos. Nesse viés, Araújo e Vilança $(2016$, p. 22) completam que "ao mesmo tempo que a interdisciplinaridade promove uma visão dos conteúdos de forma abrangente e integradora, sem fragmentos, também permite um processo de aquisição do conhecimento pleno, pautado no mundo em que está inserido".

Assim, o professor F2 destaca potencialidades da política do PROINFO no desenvolvimento de ações interdisciplinares, sobretudo quando se trata da imersão das tecnologias digitais em atividades pedagógicas. Problematizando essa questão, o docente ressalta que a interdisciplinaridade será possível à medida que as TIC forem apropriadas com clareza e conhecimento em benefício do desenvolvimento de um processo de ensino-aprendizagem interdisciplinar. Trazendo para a realidade que atua, o professor F2 finaliza sua fala justificando que pelas lacunas observadas, o PROINFO não conseguiu instituir na escola ações pautadas na interdisciplinaridade.

Ao nos debruçarmos em alguns documentos oficiais do PROINFO, como a Portaria $\mathrm{n}^{\circ}$ 522 de 9 de abril de 1997, que o instituiu Diretrizes do PROINFO, e do Decreto ${ }^{\circ} 6.300$, 12 de dezembro de 2007, que retrata a política do programa em um momento mais con- 
temporâneo, não foi possível constatar menções diretas a interdisciplinaridade. Todavia, destacamos um trecho do documento Diretrizes do PROINFO, no qual nos direciona a pensarmos sobre novas e diferentes formas de lidarmos com o conhecimento, resultado de um mundo cada vez mais tecnológico. Assim ressalta:

\begin{abstract}
Ao lado da necessidade de uma sólida formação básica, é preciso, também, desenvolver novos hábitos intelectuais de simbolização e formalização do conhecimento, de manejo de signos e representação, além de preparar o indivíduo para uma nova gestão social do conhecimento, apoiada num modelo digital explorado de forma interativa (BRASIL, 1997, p. 02).
\end{abstract}

Pensar em novos hábitos intelectuais de apropriação de conhecimento implica em diversificar e ampliar espaços de saberes, processos e metodologias. Compreendemos que isso inclui aproximações e diálogo entre diferentes campos do saber. Ao abordar a discussão sobre tecnologias e interdisciplinaridade, Araújo e Vilança reforçam:

[...] Um ensino que possibilite uma perspectiva interdisciplinar com o auxílio das tecnologias permite preparar o sujeito para conviver e cooperar em uma sociedade cada vez mais globalizada em que os conhecimentos segmentados se tornam cada vez menos capazes de dar conta da realidade (ARAÚJO; VILANÇA, 2016, p. 219).

Aliar tecnologias digitais a perspectivas de ensino interdisciplinares possibilita criar espaços de formação alinhados às demandas da sociedade contemporânea, além de desenvolver nos sujeitos a capacidade de produzir e aprender conhecimentos.

Frente a essa questão, apresentaremos o discurso do professor F3 sobre as contribuições do PROUCA para o desenvolvimento de práticas de ensino interdisciplinar, assim ele afirma:

\begin{abstract}
A interdisciplinaridade ocorre quando em uma aula consigo trabalhar assuntos unindo a vários conteúdos de outras disciplinas. O notebook, computador entre outros instrumentos pode nos ajudar nesse desafio que é o ensino interdisciplinar, pois abre um leque de estratégias de unir esses conhecimentos. O PROUCA contribuiu com a interdisciplinaridade ao oferecer uma ferramenta com essas possibilidades, por oportunizar o professor a planejar e desenvolver suas aulas em uma ferramenta que tem disponível conhecimentos de diversos campos.
\end{abstract}

Assim como o respondente anterior, também é possível perceber no discurso do professor F3 sua concepção sobre a interdisciplinaridade na qual está ligada a ideia de interação entre vários campos do conhecimento. Ultrapassando tal compreensão, Fazenda (2011, p. 104) assume que "a interdisciplinaridade parte muito mais da interação entre as pessoas do que entre os conteúdos das disciplinas. Se não há espaço para o diálogo, a interação entre as pessoas não encontrará espaço para ser exercida". Partindo dessa premissa, o espaço de diálogo, respeito mútuo e colaboração entre os sujeitos envolvidos no processo de ensino-aprendizagem são passos promissores na busca do desenvolvimento da interdisciplinaridade. É preciso ter humildade para entender que não existe conhecimento maior ou menor, para assim tecer juntos uma rede de saberes capaz de lidar com diferentes formas de conhecer o mundo. 
O professor F3 também ressalta que ao oferecer recursos digitais, o PROUCA pode contribuir com o desenvolvimento de práticas interdisciplinares. Desse modo, Lucena nos alerta que as tecnologias digitais colaboram com a produção de saberes interligados:

\begin{abstract}
O trabalho com as TIC na educação potencializa a produção de saberes construídos de forma coletiva e colaborativa, utilizando as redes sociodigitais. Essas redes são formadas por sujeitos que se comunicam, interagem, relacionam-se e desenvolvem produções colaborativas nos ambientes virtuais; ou seja, que estão imersos na cultura digital e na cultura da mobilidade. Construir redes sociodigitais na educação não é um trabalho fácil, pois não basta disponibilizar as TIC na escola para que as coisas aconteçam. As redes sociodigitais interligam pessoas e tecnologias; por isso a presença das TIC conectadas à internet, nas escolas, é apenas um primeiro passo para que essas redes possam ser constituídas na educação (LUCENA, 2016, p. 287).
\end{abstract}

Partindo disso, interligar as tecnologias digitais no processo de ensino-aprendizagem permite o diálogo mútuo entre diferentes campos do conhecimento, tendo em vista a dimensão de utilização pelos sujeitos praticantes da/na cultura digital, nos quais, em seu cotidiano, se comunicam, interagem e produzem informação e conhecimento de forma colaborativa e coletiva nos espaços virtuais. No entanto, tal prática configura-se como um desafio vivenciado no contexto escolar, pois disponibilizar tais artefatos não garante propostas pautadas na aproximação entre as áreas de conhecimento.

Podemos constatar que o foco principal das políticas de tecnologia educacional PROINFO e PROUCA pauta-se desde sua criação na inserção das TIC no cenário educacional. Ao analisarmos as respostas dos professores participantes desse estudo, fica evidente que tal imersão ocorreu de maneira isolada de elementos essenciais como a formação de professores para o uso das tecnologias digitais. Lucena (2016) observa que:

Um dos principais problemas apresentados como fator da não utilização das TIC na escola é a formação de professores. Isso porque, em geral, os programas governamentais resumem a formação continuada de professores em pequenos cursos ou oficinas com carga horária de 40 a 80 horas, insuficientes para a reflexão crítica sobre o uso das TIC (LUCENA, 2016, p. 285-286).

Sobre tal questão, Echalar e Peixoto (2017) nos informam que a formação dos docentes e dirigentes envolvidos com o PROUCA aparece como um dos quatro pilares deste programa (BRASIL, 2010). Ao aprofundar essa discussão, os autores apresentam críticas nas quais nos instigam a reflexão ao destacar que o tipo de formação oferecida aos professores pelo PROUCA apresenta-se como um fator dificultador e desafiador na promoção da inclusão digital de alunos e professores, pois pauta-se em uma

Formação em serviço e cursos obrigatórios de caráter modular, com a duração de um ano. Tais cursos foram estruturados com base numa racionalidade instrumental que adota a fragmentação dos conteúdos e o dualismo entre a técnica e o pedagógico como referência (GATTI, 2010; SÁ; ENDLISH, 2014 apud ECHALAR, 2015, p. 66-67). 
Cabe ressaltar que essa modalidade adotada para a formação de professores e gestores vinculados a escolas beneficiadas pelo PROUCA reverbera na atuação da política do programa no contexto da prática, tendo em vista que ao fragmentar os conteúdos do curso e desvincular a formação técnica e pedagógica dos professores, irá fortalecer ainda mais a ideia do conhecimento amarrado em divisórias disciplinares, distante da interdisciplinaridade que temos tratado nesse estudo.

Sobre o PROINFO, vale salientar que partindo de suas reformulações em 2007, a política do programa passa a ter como enfoque a formação de professores e gestores, desse modo, o Programa de Formação Continuada em Tecnologia Educacional - ProInfo Integrado - é criado para oferecer cursos de capacitação, dentre os quais citamos "Introdução a Educação Digital", "Tecnologias na Educação: ensinando e aprendendo com as TICS" e "Elaboração de Projetos".

Tais cursos são ofertados por meio do Ambiente Colaborativo de Aprendizagem e-ProInfo ${ }^{3}$. Entendemos que a utilização de uma plataforma digital pelos professores para participarem dos cursos oportuniza que estes construam experiências com as tecnologias digitais ao mesmo passo que adquirem conhecimentos. Assim, Alonso (et al., 2014, p. 161) sinalizam "para ensinar com tecnologias, é preciso aprender com tecnologias, para ser um 'aprendiz continuado' [...]”. Colabora com tal discussão Castro quando afirma:

\begin{abstract}
A formação de professores na área de tecnologia educacional, se faz necessária para efetivar a apropriação das TICs no ambiente escolar, o que constitui a proposta do PROINFO. Entretanto, no nosso entendimento, essa apropriação passa necessariamente por canais e espaços, por meio dos quais os professores possam, cotidianamente, apreender, interpretar e posicionar-se frente à política de tecnologia educacional. Nessa perspectiva, a eficácia dos processos formativos do PROINFO estará vinculada à viabilização de tais espaços de participação (CASTRO, 2011, p. 106).
\end{abstract}

Formar professores para inserir as TIC em processos educativos precisa ser um pilar para qualquer política voltada a este propósito, uma formação implicada que vise estimular os professores a participação comprometida com o desenvolvimento de competências dos seus alunos praticantes na/da cultura digital.

A análise dos programas PROINFO e PROUCA nos faz perceber que apesar de serem norteados por objetivos distintos. Enquanto o primeiro objetivou promover o uso pedagógico da informática na rede pública de Educação Básica, o segundo buscou promover a inclusão digital nas escolas mediante a aquisição e utilização das TICS. Tais políticas estavam envolvidas por escopos similares, a saber: aproximação da escola com o contexto da sociedade conectada em rede; apropriação dos recursos tecnológicos no processo de ensino e aprendizagem; promoção da inclusão digital; formação de estudantes preparados para lidar com as novas exigências do mercado de trabalho.

3 e-ProInfo: uma plataforma digital a qual possibilita que professores da rede pública realizem cursos com outros professores. 


\section{CONSIDERAÇões FINAIS}

Este artigo teve como propósito analisar como as propostas dos programas governamentais PROUCA e PROINFO, colaboram com práticas curriculares de ensino interdisciplinar. Para o desenvolvimento deste trabalho, tomamos como base a proposta expressas nos documentos oficiais dos referidos programas, bem como aplicação de um formulário eletrônico onde os respondestes foram três docentes que atuam tais propostas. Adentramos nos documentos e analisamos o formulário preenchido a partir do Ciclo de Políticas de Bowe, Ball e Gold (1998) para entender o seu processo integrante por meio dos contextos nomeados pelos autores de contexto da influência, contexto da produção de texto e contexto da prática.

Durante o estudo, encontramos alguns aspectos merecedores de destaque. O primeiro, evidenciado nas falas dos três docentes participantes desse estudo, nos mostra que as propostas dos programas se apresentam propícias ao desenvolvimento de práticas interdisciplinares, bem como para a promoção da inclusão digital no âmbito escolar. Todavia, as lacunas no processo de implementação, sentidas pelos docentes no contexto da prática, ecoam como fator desfavorável para atingir tais metas. Percebemos ainda que nas instituições pesquisadas, a presença das TIC através do PROINFO e PROUCA não significou garantia da efetivação de uma cultura digital, tendo em vista as limitações na apropriação de artefatos tecnológicos tanto para professores quanto para alunos.

Ressaltamos que as políticas do PROINFO e PROUCA foram assentadas principalmente na imersão das TIC e seu uso pedagógico nas instituições escolares. No entanto, é marcante nos discursos dos professores os entraves enfrentados na atuação dessas políticas, dentre os quais citamos: falha no acompanhamento das ações dos programas, número insuficiente de recursos tecnológicos, baixa ou falta de conexão à internet, carência de cursos de formação para atuar tais políticas.

Essa realidade não condiz com as principais intencionalidades, estratégias traçadas, ações, metas a serem alcançadas pelos programas que, no caso do PROINFO, atribui a importância ao uso das TIC como "vital para a sociedade brasileira que a maioria dos indivíduos saiba operar com as novas tecnologias da informação e valer-se destas para resolver problemas, tomar iniciativas e se comunicar" (PROINFO, 1997, p. 02).

No processo de análise dessas propostas, ficou evidente que tais políticas não visaram apenas distribuir recursos tecnológicos nas escolas, desse modo a participação dos NTE, MEC, FNDE não se encerra quando os computadores e laptops chegam às escolas. Muito mais que isso, é necessário que as iniciativas dos programas ofereçam suportes às intuições escolares, acompanhando e avaliando o desenvolvimento dos programas, além de sensibilizar e incentivar os docentes para o uso implicado na busca de ultrapassar a prerrogativa de utilização como meros instrumentos ou ferramentas para aulas expositivas e não dialogadas.

Paralelo a isso, o estudo sobre as políticas de tecnologias educacionais, nos fez perceber que a escola, enquanto instituição imbuída de seus interesses e anseios, corroboram com a ressignificação das políticas oficiais, nesse caso, a política não é meramente implantada na escola, tendo em vista que a escola interpreta o texto político e, ao longo desse pro- 
cesso, ocorre a ressignificação ou criação de outras políticas através das propostas oficiais do Estado. Nessa interpretação, as políticas podem ser atuadas de diversas formas como revelado pelos discursos dos professores pesquisados.

\section{REFERÊNCIAS}

ALONSO, Katia Marosov et al. Aprender e ensinar em tempos de Cultura Digital. Unirede: revista de Educação à distância. V. 1, n. 1. Jul. 2014.

ARAUJO, Elaine Vasquez Ferreira de; VILAÇA, Márcio Luiz Corrêa. Tecnologia, sociedade e educação na era digital. Duque de Caxias. RJ: Unigranrio, 2016. Cap. 1. p. 17- 40.

BALL, Stephen. J; MARGUIRE, Meg; BRAUN, Annette. Como as escolas fazem as políticas: atuação em escolas secundárias. Editora UEPG: Ponta Grossa. Paraná, 2016.

BONGIOVANI, Eduardo. ARAÚJO, Luiz Eduardo de. A contribuição da informática pedagógica na formação do professor e do aluno-técnico. Paraná, 2013. Disponível em: $\quad<$ http://www.diaadiaeducacao.pr.gov.br/portals/cadernospde/pdebusca/producoes pde/2013/2013_uenp_dtec_artigo_eduardo_bongiovani.pdf>. Acesso em: 15 Abr. 2019.

BOWE, R.; BALL, S.; GOLD. A. Reforming education \& changing schools: case studies in policy sociology. London: Routledge, 1992.

BRASIL. Presidência da República, Casa civil. Decreto 6.300/2007. Dispõe sobre o Programa Nacional de Tecnologia Educacional - PROINFO. Brasília, DF, 2007. Disponível em: $\quad<$ https://presrepublica.jusbrasil.com.br/legislacao/94218/decreto-6300-07\#art-1>. Acesso em: 07 Mar. 2020.

. Ministério da Educação e do Desporto. Gabinete do Ministro. Portaria n ${ }^{0}$ 522, de 9 de abril de 1997. Autoriza a criação do Programa Nacional de Informática na Educação - ProInfo. Diário da República Federativa do Brasil. Brasília, DF, 1997. Disponível em: $<$ http://www.dominiopublico.gov.br/download/texto/me001167.pdf $>$. Acesso em 07 mar. 2020 .

. ProInfo - Diretrizes. Brasília, DF, 1997. Disponível em: <http://www.gestaoescolar.diaadia.pr.gov.br/arquivos/File/pdf/proinfo_diretrizes1.pdf $>$. Acesso em: 13 mar. 2019.

. Lei $\mathrm{n}^{\circ} 12.249$, de 11 de junho de 2010. Disponível em: http://www.planalto.gov. br/ccivil_03/_Ato2007-2010/2010/Lei/L12249.htm. 2010a. Acesso em: 04 jun. 2019.

. Ministério da Educação e Cultura. UCA- Projeto um computador por aluno: formação Brasil. Brasília, DF, 2009. Disponível em: <http://www.consultaesic.cgu.gov. 
br/busca/dados/lists/pedido/attachments/457157/resposta_pedido_vi\%20-\%20uca_projeto_formao_brasil.pdf>. Acesso em: 04 jun. 2019.

CASTRO, Márcia Correa E. Enunciar Democracia e Realizar o Mercado Políticas de Tecnologia na Educação até o Proinfo Integrado (1973-2007). Dissertação (Mestrado em Educação) - Pontifícia Universidade Católica do Rio de Janeiro, Rio de Janeiro, 2011.

CORDEIRO, S. F. N. BONILLA, M. H. S. Educação e tecnologias digitais: políticas públicas em debate. $5^{\circ}$ SENID, 2018. Disponível em: <https://www.upf.br/_uploads/Conteudo/senid/2018-artigos-completos/178958.pdf>. Acesso em: 10 Abr. 2019.

COSCARELLI, Carla; RIBEIRO, Ana Elisa. Letramento digital: aspectos sociais e possibilidades pedagógicas. Belo Horizonte, Ceale. Editora Autêntica, 2017.

ECHALAR, Adda Daniela Lima Figueiredo; PEIXOTO, Joana. Programa Um Computador por Aluno: o acesso às tecnologias digitais como estratégia para a redução das desigualdades sociais. Ensaio: Avaliação de Políticas Públicas em Educação, Rio de Janeiro, v. 25, n. 95, p.393-413, jun. 2017. Disponível em: <http://www.scielo.br/pdf/ensaio/ v25n95/1809-4465-ensaio-S0104 40362017002501155.pdf>. Acesso em 03 mai. 2019.

JUCIEUDE, Lucena Evangelista et al. Meios de comunicação e escola na contemporaneidade: conflitos e diálogos possíveis. Educere Et Educare: Revista de Educação, Campus de Cascavel. v. 2. n. 23. p. 1-12. jul. 2016.

LARROSA, J. Notas Sobre a experiência e o Saber de Experiência. Espanha: Huahuahua, 2001.

LOPES, Alice Casimiro; MACEDO, Elizabeth. Teorias de currículo. São Paulo: Cortez, 2011.

LUCENA, S. Culturas digitais e tecnologias móveis na educação. Educar em Revista, [s. 1.], n. 59, p. 277-290, mar. 2016. FapUNIFESP (SciELO). Disponível em: $<$ http://www. scielo.br/scielo.php?pid=S010440602016000100277\&script $=$ sci_abstract\&tlng=pt $>$. Acesso em: 17 out. 2019.

MAINARDES, Jefferson. Abordagem do ciclo de políticas: uma contribuição para a análise de políticas educacionais. Educação e Sociedade, Campinas, v. 27, n. 94, p. 47-69, jan./ abr., 2006.

MINAYO, M. C. S. Análise qualitativa: teoria, passos e fidedignidade. Rio de Janeiro: Ciência \& Saúde Coletiva, 2011.

MOREIRA, F. M. T. D. As TICs no trabalho pedagógico interdisciplinar. 2003. Universidade de Brasília, Brasília- DF, 2003. Disponível em: <http://bdm.unb.br/bitstream/10483/7985/1/2013_FlaviaMariaTomazDiasMoreira.pdf>. Acesso em: 03 Mai. 2019. 
NASCIMENTO, João Kerginaldo Firmino do. Informática aplicada à educação. Brasília. Universidade de Brasília, 2009. Disponível em: <http://portal.mec.gov.br/index.php?option $=$ com_docman\&view $=$ download\&alias $=606$-informatica-aplicada-a-educacao\&Itemid=30192> . Acesso em: 15 Abr. 2019.

(ORG.), Ivani Fazenda. O QUE É INTERDISCIPLINARIDADE? 2008. Disponível em: <https://filosoficabiblioteca.files.wordpress.com/2013/11/fazenda-org-o-que-c3a9-interdisciplinaridade.pdf $>$. Acesso em: 15 Abr. 2019.

RIBEIRO, M. R. F. A sala de aula no contexto da cibercultura: formação docente e discente em atos de currículo. 2015. 207 f. - Faculdade de Educação, Universidade do Estado do Rio de Janeiro, Rio de Janeiro, 2015.

RONSANI, Isabel Luvison. Informática na Educação: uma análise do PROINFO. Histedbr On-line, [s.i.], v. 1, n. 16, p.1-23, dez. 2004. Disponível em: <https://www.fe.unicamp. br/pf-fe/publicacao/4790/art8_16.pdf>. acesso em: 03 mai. 2019.

SANTOS, Edméa Oliveira dos. Educação online: cibercultura e pesquisa-formação na prática docente / Edméa Oliveira dos Santos. - 2005. 351 f.

SANTOS, Jean Mac Cole Tavares. Políticas para o ensino médio: a criação do currículo no contexto escolar. Revista Linhas. Florianópolis, v. 17, n. 33, p. 261-283, jan./abr. 2016.

SERRES, M. Polegarzinha: uma nova de viver em harmonia, de pensar as instituições, de ser e de saber. Bertrand Brasil, Rio de Janeiro. 2013.

SOUSA, Maurício de. Apontamentos teórico-metodológicos: contribuições de Stephen J. Ball para as pesquisas de políticas educacionais. Revista de Estudios Teóricos y Epistemológicos en Política Educativa, v. 3, 2019. Disponível em: file:///C:/Users/rober/Downloads/ 13446-Texto\%20do\%20artigo-209209216950-1-10-20190408.pdf. Acesso em 11 fev. 2020.

SOUZA, Mariana Aranha de. FAZENDA, Ivani Catarina Arantes. Interdisciplinaridade, currículo e tecnologia: um estudo sobre práticas pedagógicas no ensino fundamental. Revista Ibero - 2017. Disponível em: $<$ https://periodicos.fclar.unesp.br/iberoamericana/article/viewFile/8303/6561>. Acesso em: 15 de Abr. 2019.

SCHUCHTER, L. H. Escola.edu: as políticas públicas de formação docente para o uso das tecnologias digitais na rede municipal de ensino de Juiz de Fora. Universidade Federal de Juiz de Fora. Juiz de Fora, 2017. Disponível em: <https://repositorio.ufjf.br/jspui/handle/ ufjf/5993>. Acesso em: 03 Mai 2019.

TAVARES, N. R. B. História da informática no Brasil. São Paulo. Disponível em: <http:// www.apadev.org.br/pages/workshop/historiaInf.pdf>. Acesso em: 15 Abr. 2019. 
VERDUM, P. Prática Pedagógica: o que é? O que envolve? Revista Educação Por Escrito, Porto Alegre, v. 4. n. 1. p. 91-105. jul. 2013. Disponível em: $<$ http://revistaseletronicas. pucrs.br/ojs/index.php/porescrito/article/viewFile/14376/9703>. Acesso em: 15 Jun 2019.

\section{Dados das Autoras}

\section{Roberta Mirnas de Oliveira Gomes}

Mestranda em Ensino da Universidade do Estado do Rio Grande do Norte (UERN), Mossoró/RN, Brasil. robertamirnas@gmail.com

\section{Jean Mac Cole Tavares Santos}

Doutor em Educação pela Universidade Federal da Paraíba (UFPB). Docente da Universidade do Estado do Rio Grande do Norte (UERN), Mossoró/RN, Brasil. maccolle@hotmail. com

Submetido em: 17-08-2020

Aceito em: 01-02-2021 